\title{
Fragmental Method KowWIN as the Powerful Tool for Prediction of Chromatographic Behavior of Novel Bioactive Urea Derivatives
}

\author{
Jolanta Flieger, *,a Matgorzata Tatarczak-Michalewska, ${ }^{a}$ Anna Kowalska, ${ }^{a}$ Marzena \\ Rządkowska, ${ }^{b}$ Elżbieta Szacoń, ${ }^{b}$ Agnieszka A. Kaczor ${ }^{b, c}$ and Dariusz Matosiuk ${ }^{b}$ \\ ${ }^{a}$ Department of Analytical Chemistry and ${ }^{b}$ Department of Synthesis and Chemical Technology of \\ Pharmaceutical Substances with Computer Modeling Lab, Faculty of Pharmacy with Division of \\ Medical Analytics, Medical University of Lublin, 4A Chodźki St., PL-20093 Lublin, Poland \\ ${ }^{c}$ School of Pharmacy, University of Eastern Finland, Yliopistonranta 1, \\ P.O. Box 1627, FI-70211 Kuopio, Finland
}

\begin{abstract}
A series of the new urea derivatives with antinociceptive activity has been chromatographically evaluated using reversed phase materials: Zorbax Extend-C18, Cogent UDC Cholesterol with organicaqueous eluent systems with two organic modifiers (methanol and acetonitrile). The chromatographic lipophilicity parameters: $\log k_{\mathrm{w}}, S$ and $\varphi_{0}$ were determined basing on linear relationship between $\log k$ values and concentration of organic mobile phase modifier. The structure-retention studies revealed that the retention mechanism for all studied urea derivatives is uniform for the proposed chromatographic systems. However, a few exceptions were noticed. Derivatives containing nonpolar substituents in the imidazole ring acted as outliers for cholesterol column. In turn, the derivative containing ester polar substituent acted as an outlier in conventional reversed-phase system. Quantitative relationships based on a wide set of established computational molecular descriptors and experimental chromatographic data were also developed. Through a systematic study, by using the principal component analysis, fragmental method KowWIN appeared to be the most powerful software to produce reliable estimations of experimental retention parameters obtained on cholesterol column.
\end{abstract}

Keywords: urea derivatives, reversed-phase HPLC, lipophilicity, principal component analysis

\section{Introduction}

Lipophilicity is one of the most important parameters in drug design, playing a key role in kinetic and dynamic aspects of drug action. ${ }^{1}$ The importance of lipophilicity in predicting ADMET (absorption, distribution, metabolism, excretion, toxicity) properties has been well documented. ${ }^{1-3}$

It should be emphasized, however, that the number of existing experimental lipophilicity scales is extremely low in comparison to high number of compounds for which such data are essential. Among analytical sophisticated techniques (for instance: counter-current chromatography (CCC), micellar liquid chromatography (MLC), micellar capillary electrophoresis (MCE), microemulsion liquid chromatography), reversed phase high-performance liquid chromatography (RP-HPLC) appears to be the most common..$^{4-12}$

\footnotetext{
*e-mail: j.flieger@umlub.pl
}

At the beginning, the chromatographic retention parameters measured by monocratic RP-HPLC were used to estimate lipophilicity. However, many of the current papers describe application of retention factors estimated by polycratic methods. According to this last approach, the chromatographic lipophilicity values are derived from the linear relationship between retention $(\log k)$ and the volume fraction $(\varphi)$ of organic solvent in the mobile phase. ${ }^{13-16}$ The lipophilicity parameters were calculated utilizing the following linear equation:

$\log k=-S \varphi+\log k_{\mathrm{w}}$

The regression parameters: the intercept $\left(\log k_{\mathrm{w}}\right)$, the slope $(S)$ and the ratio $-\log k_{\mathrm{w}} / S$ known as $\varphi_{0}$ are considered as relative lipophilicity scales. ${ }^{17,18}$ The quotient $\varphi_{0}$ is equivalent to the organic solvent content which is required to make retention time double the dead time. Frequently, this parameter has showed a better correlation with the $\log P$ values than the remaining chromatographic 
lipophilicity parameters. ${ }^{17,19,20}$ Moreover, the $\varphi_{0}$ values are the basis for deriving high-throughput lipophilicity data from gradient retention time. The $\log k_{\mathrm{w}}$ factor corresponds to the theoretical retention of the analyte in pure water or a buffer. The introduction of this parameter was intended to eliminate the influence of the organic solvent for the retention process. The $S$ parameter is associated with retention mechanism and corresponds to the difference in retention of the analyte $(\log k)$ in pure water $(\varphi=0)$ and pure modifier $(\varphi=1)$.

To construct chromatographic system for lipophilicity measurement, different stationary materials have been tested. Most frequently, octadecyl silica stationary phase and methanol-aqueous or buffered mobile phase have been applied. This system provides significant correlations between theoretical or experimental logarithmic partition coefficient $(\log P)$ and chromatographically measured $\log k_{\mathrm{w}}$ for structurally analogous compounds. It should be stressed that in some cases these relationships require corrections considering ionization of the analytes. ${ }^{21,22}$

In recent years, several adsorbents imitating the biological membranes have been developed. The artificial biological membranes with immobilized phosphatidylcholine, ceramides, keratin, proved to be useful in drug design process, to compare lipophilicity, modeling bioavailability or anticipate the process of the cell membrane permeation. Nowadays, stationary phases with immobilized cholesterol, which is an important component of biological membranes are increasingly popular. ${ }^{23,24}$ Cholesterol column possesses many advantageous properties like, for instance, low silanol activity or liquidcrystalline behavior owing to their tendency to aggregate..$^{25}$

Chromatographically estimated lipophilicity expressing affinity of molecules to hydrophobic phase simulating permeation through biological barriers was used firstly as a descriptor in QSAR (quantitative structure-activity relationship) by Hansch et al. ${ }^{26}$ QSAR approach by introductory screening of drug candidates enabled to reduce failed clinical trials lowering the costs of drug discovery.

Beside experimental measurements there are many software packages (e.g., Clog P, Alog Ps, ACD-Labs) to compute $\log P$ basing on molecular structure. As a consequence of varied algorithms applied by different softwares, the calculated values are not consistent with each other.

The aim of this study was to estimate the chromatographic behavior for a set of new urea derivatives covering broad structural diversity. Substituted urea derivatives belong to important class of molecules with a large spectrum of biological properties. Basing on our previous studies, ${ }^{27}$ synthesized $N$-substituted 1-alkyl-4-aryl(arylalkyl) imidazolidyn-2-ylidene ureas exhibit antinociceptive and serotonergic activity.

Chromatographic experiments were conducted on octadecyl and cholesterol stationary phases. Owing to their similarity to biological membranes, both adsorbents can be utilized to anticipate affinity of analytes to the cell membranes. RP-HPLC derived parameters were measured with the aim to construct not only alternative lipophilicity scale, but also to analyze "congenerity" of the studied compounds in context of their behavior in partition systems.

To compare the experimental and calculated indices, the principal component analysis (PCA) was employed, revealing the similarities between all the variables and structural features.

The objective of the current study was to develop the regression model to predict reliable lipophilicity of urea derivatives using chromatographic results and computational descriptors based on their molecular structures. Such model can be useful for accurate prediction of the permeability or affinity to biological membranes for examined compounds, as well as for those belonging to the same chemical domain (i), to select outliers (ii) and to choose theoretical descriptor reflecting the best behavior of urea derivatives in partition systems (iii).

\section{Experimental}

The urea derivatives investigated in the study (Figure 1) were synthesized in Department of Organic Chemistry, Medical University of Lublin. The synthesis procedure was described previously. ${ }^{23}$ The structures of all the investigated solutes were confirmed by gas chromatography-mass spectrometry (GC-MS) analysis, ${ }^{1} \mathrm{H}$ nuclear magnetic resonance (NMR), ${ }^{13} \mathrm{C}$ NMR and infrared (IR) analysis and their purity was assessed by elemental analysis. HPLC grade methanol $(\mathrm{MeOH})$, acetonitrile $(\mathrm{ACN})$ and chromatographic reagents were obtained from E. Merck (Darmstadt, Germany).

The retention factors were measured with a liquid chromatograph LaChrom HPLC Merck Hitachi (E. Merck, Darmstadt, Germany) equipped with diode array detector, column oven L-7350 and solvent degasser L-7612. The columns were a Zorbax Extend-C18 $(150 \mathrm{~mm} \times 4.6 \mathrm{~mm}$ i.d., $5 \mu \mathrm{m}$, pore size: $80 \AA$, surface area: $180 \mathrm{~m}^{2} \mathrm{~g}^{-1}$ ) from Agilent Technologies (Santa Clara, CA, USA) and Cogent UDC Cholesterol $(150 \mathrm{~mm} \times 4.6 \mathrm{~mm}$ i.d., $4 \mu \mathrm{m}$, pore size: $100 \AA ̊$; MicroSolv Technol. Corp., New York, USA). The mobile phase consisting of organic solvent and water was filtered through a Nylon 66 membrane filter $(0.45 \mu \mathrm{m})$ Whatman (Maidstone, England) by the use of a filtration apparatus. 
<smiles>[R]c1ccc(CNC(=O)NC2=NCCN2c2ccccc2[R])cc1</smiles>

Structure 1<smiles>[R1]NC(=O)NC1=NC(c2ccccc2)CN1C</smiles>

Structure 2<smiles>[R1]NC(=O)NC1=NC(c2ccc(C)cc2)CN1C</smiles>

Structure 3<smiles>[R]NC(=O)NC1=NC(c2ccccc2)CN1C</smiles>

Structure 4<smiles>[R1]NC(=O)NC1=NC(c2ccc(C)cc2)CN1C</smiles>

Structure 5<smiles>[R]NC(=O)NC1=NC(c2ccccc2)CN1CC</smiles><smiles>[R]NC(=O)Nc1nc2ccccc2[n+]([O-])n1</smiles>

Structure 7<smiles>[R]c1ccc(S(=O)(=O)N2CCN(c3ccccc3)/C2=N\C(=O)NCC(=O)OCC)cc1</smiles>

Structure 8

\begin{tabular}{lcccc}
\hline Structure & No. & $\mathrm{R}$ & $\mathrm{R}_{1}$ \\
\hline 1 & $\mathbf{1}$ & $4-\mathrm{CH}_{3}$ & $4-\mathrm{Cl}_{2}$ \\
2 & $\mathbf{2}$ & - & $\mathrm{CH}_{2} \mathrm{CH}_{2} \mathrm{C}_{6} \mathrm{H}_{5}$ \\
2 & $\mathbf{3}$ & - & $\mathrm{C}_{6} \mathrm{H}_{5}-4-\mathrm{COOC}_{2} \mathrm{H}_{5}$ \\
3 & $\mathbf{4}$ & - & $\mathrm{CH}_{2} \mathrm{C}_{6} \mathrm{H}_{5}$ \\
3 & $\mathbf{5}$ & - & $\mathrm{CH}_{2} \mathrm{CH}_{2} \mathrm{C}_{6} \mathrm{H}_{5}$ \\
3 & $\mathbf{6}$ & - & $\mathrm{C}_{6} \mathrm{H}_{5} 4-\mathrm{COOC}_{2} \mathrm{H}_{5}$ \\
4 & $\mathbf{7}$ & - & $\mathrm{C}_{5} \mathrm{H}_{9}$ \\
5 & $\mathbf{8}$ & - & $\mathrm{C}_{6} \mathrm{H}_{5}-4-\mathrm{COCH}_{3}$ \\
5 & $\mathbf{9}$ & - & $\mathrm{C}_{5} \mathrm{H}_{9}$ \\
6 & $\mathbf{1 0}$ & - & $\mathrm{C}_{6} \mathrm{H}_{5} 4-\mathrm{COCH}_{3}$ \\
6 & $\mathbf{1 1}$ & - & $\mathrm{C}_{5} \mathrm{H}_{9}$ \\
6 & $\mathbf{1 2}$ & - & $\mathrm{C}_{6} \mathrm{H}_{5}-4-\mathrm{COOC}_{2} \mathrm{H}_{5}$ \\
7 & $\mathbf{1 3}$ & - & $\mathrm{CH}_{2} \mathrm{CH}_{2} \mathrm{C}_{6} \mathrm{H}_{5}$ \\
7 & $\mathbf{1 4}$ & $\mathrm{H}$ & $\mathrm{C}_{6} \mathrm{H}_{5}-4-\mathrm{COCH}_{3}$ \\
8 & $\mathbf{1 5}$ & $2-\mathrm{OCH}_{3}$ & $4-\mathrm{CH}_{3}$ \\
8 & $\mathbf{1 6}$ & $4-\mathrm{OCH}_{3}$ & $4-\mathrm{CH}_{3}$ \\
8 & $\mathbf{1 7}$ & $2,3-\mathrm{CH}_{3}$ & $4-\mathrm{CH}_{3}$ \\
8 & $\mathbf{1 8}$ & $4-\mathrm{Cl}_{3}$ & $4-\mathrm{CH}_{3}$ \\
8 & $\mathbf{1 9}$ & $\mathrm{H}$ & $4-\mathrm{CH}_{3}$ \\
8 & $\mathbf{2 0}$ & & $4-\mathrm{Cl}^{2}$
\end{tabular}

Figure 1. Investigated compounds. 
Retention data were recorded at a flow-rate of

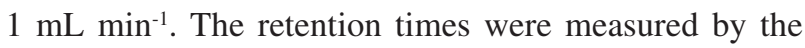
diode-array detector (DAD) at appropriate wavelength chosen accordingly with the spectra recorded in the range of $200-400 \mathrm{~nm}$. The methanolic stock solutions $\left(1.0 \mathrm{mg} \mathrm{mL}^{-1}\right)$ were injected through a Rheodyne injector valve with a $20 \mu \mathrm{L}$ loop. Typical injection volumes were $3 \mu \mathrm{L}$. Uracil was used as the unretained marker.

The lipophilicity parameters were calculated utilizing linear equation. At least four organic solvent concentrations were used to construct the regression curve. HPLC analysis was performed under isocratic conditions at ambient temperature.

The investigated compounds were first modeled using the LigPrep protocol from the Schrödinger Suite (LigPrep, Version 2.4: Schrödinger, LLC, New York 2010). In order to sample different protonation states of ligands in physiological pH, Epik module was used (Epik, Version 2.1: Schrödinger, LLC, New York 2010). The molecular structures of the compounds in the ground state (in vacuo) were further optimized with the B3LYP DFT (the variant of DFT method using Becke's three parameter hybrid functional (B3) ${ }^{28}$ with correlation functional such as the one proposed by Lee et al. ${ }^{29}$ (LYP)) using 6-31G(d,p) basis set as included in Gaussian09. ${ }^{30}$

Lipophilicity was calculated with the Virtual Chemistry Laboratory $^{31}$ (ALOGPs, AClogP, miLogP, ALOGP, MLOGP, KOWWIN, XLOGP2, XLOGP3), Sybyl-X v. 1.2
(SYBYL-X 1.2, Tripos International, 1699 South Hanley Rd., St. Louis, Missouri, 63144, USA), MOE Molecular Environment (MOE Molecular Operating Environment 2009.10, Chemical Computing Group), Schrödinger suite of software Schrödinger suite of software (Schrödinger, LLC, New York 2010) and Discovery Studio v. 3.1 (BIOVIVA). HOMO and LUMO energy and dipole moment were calculated with Gaussian09.30 Molar mass, bloodbrain barrier permeation and solubility were calculated with Discovery Studio v. 3.1 Molecular area (3D), molecular volume (3D), topological polar surface area (TPSA, 2D) and van der Waals donor and acceptor surface (2D) were calculated with MOE Molecular Environment. Polarizability and molar refractivity were calculated with Schrödinger suite of software. Distribution at different $\mathrm{pH}$ was calculated with ACDLabs software (ACD/I-Lab, Advanced Chemistry Development, Inc., Toronto, On, Canada, www.acdlabs.com, 2014). All data were examined by correlation analysis with significant level $(p<0.05)$ and principal component analysis (PCA) was performed by statistical software package PQStat version v.1.6.0 considering the following variables (Tables 1 and 2; Tables $\mathrm{S} 1$ and $\mathrm{S} 2$ from Supplementary Information): $\operatorname{Alog}_{\mathrm{s}}(1)$, $\mathrm{AC} \log \mathrm{P}(2), \mathrm{A} \log \mathrm{P}(3), \mathrm{M} \log \mathrm{P}(4), \mathrm{KOWWIN}(5), \mathrm{X} \log \mathrm{P} 2$ (6), XlogP3 (7), clogP Sybyl (8), $\log \mathrm{P}$ MOE (9), AlogP98 Discovery Studio (10), logP Schrödinger suite (11), HOMO, eV (12), LUMO, eV (13), Mol. Mass (14), Area (15), TPSA (16), VDW surface donor 2D (17), VDW surface acceptor

Table 1. Lipophilicity calculated using different algorithms. Variables numbers are collected in experimental part

\begin{tabular}{|c|c|c|c|c|c|c|c|c|c|c|c|}
\hline No. & ALOGPs & $\mathrm{AC} \log \mathrm{P}$ & ALOGP & MLOGP & KOWWIN & XLOGP2 & XLOGP3 & $\begin{array}{l}\text { clogP } \\
\text { Sybyl }\end{array}$ & $\log \mathrm{P} \mathrm{MOE}$ & alogP98 DS & $\begin{array}{l}\log \mathrm{P} \\
\text { Schr. }\end{array}$ \\
\hline 1 & 2.9 & 3.4 & 4.3 & 3.3 & 4.4 & 4.1 & 2.8 & 5.2 & 3.5 & 3.7 & 3.3 \\
\hline 2 & 2.6 & 2.9 & 3.4 & 2.7 & 3.2 & 3.1 & 2.5 & 4.2 & 2.8 & 2.9 & 3.1 \\
\hline 3 & 2.9 & 3.2 & 3.3 & 2.7 & 3.5 & 3.1 & 2.3 & 4.7 & 2.9 & 2.8 & 3.3 \\
\hline 4 & 2.5 & 2.9 & 3.6 & 2.7 & 3.2 & 3.4 & 2.4 & 4.8 & 3.1 & 3.1 & 3.3 \\
\hline 5 & 2.8 & 3.2 & 3.9 & 3.0 & 3.7 & 3.5 & 2.8 & 4.7 & 3.1 & 3.4 & 3.6 \\
\hline 6 & 3.3 & 3.5 & 3.8 & 2.9 & 4.0 & 3.6 & 2.6 & 5.2 & 3.2 & 3.3 & 3.7 \\
\hline 7 & 2.0 & 2.5 & 2.9 & 2.3 & 2.8 & 2.5 & 1.8 & 3.6 & 2.5 & 2.4 & 2.6 \\
\hline 8 & 2.6 & 3.0 & 3.3 & 2.7 & 3.0 & 3.1 & 2.1 & 4.1 & 2.8 & 2.8 & 3.3 \\
\hline 9 & 2.3 & 2.8 & 3.4 & 2.5 & 3.3 & 2.9 & 2.1 & 4.1 & 2.8 & 2.9 & 3.1 \\
\hline 10 & 2.9 & 3.1 & 3.2 & 2.7 & 2.9 & 3.0 & 2.1 & 4.2 & 2.8 & 2.7 & 3.1 \\
\hline 11 & 2.7 & 2.9 & 3.3 & 2.5 & 3.2 & 2.9 & 2.1 & 4.1 & 2.9 & 2.8 & 2.9 \\
\hline 12 & 3.3 & 3.6 & 3.7 & 2.9 & 4.0 & 3.6 & 2.6 & 5.2 & 3.2 & 3.1 & 3.6 \\
\hline 13 & 1.8 & 3.9 & - & - & 1.8 & 1.3 & 2.9 & 2.5 & 2.4 & 1.9 & 2.7 \\
\hline 14 & 1.5 & 3.7 & - & - & 1.1 & 0.8 & 2.2 & 1.5 & 2.1 & 1.4 & 2.4 \\
\hline 15 & 2.1 & 2.4 & 4.2 & 2.1 & 2.3 & 4.5 & 2.7 & 4.5 & 2.6 & 2.9 & 3.1 \\
\hline 16 & 1.9 & 2.3 & 4.2 & 1.9 & 2.4 & 4.4 & 2.7 & 4.4 & 2.6 & 2.8 & 3.0 \\
\hline 17 & 2.0 & 2.3 & 4.2 & 1.9 & 2.4 & 4.4 & 2.7 & 4.4 & 2.6 & 2.8 & 3.0 \\
\hline 18 & 2.5 & 3.0 & 5.2 & 2.5 & 3.4 & 5.1 & 3.4 & 5.4 & 3.2 & 3.8 & 4.0 \\
\hline 19 & 2.7 & 3.0 & 4.9 & 2.6 & 3.0 & 5.1 & 3.3 & 5.2 & 3.2 & 3.5 & 3.7 \\
\hline 20 & 2.8 & 2.7 & 4.4 & 2.4 & 2.4 & 4.7 & 3.0 & 4.7 & 2.9 & 3.0 & 3.2 \\
\hline
\end{tabular}


Table 2. The absolute values of the regression parameters determined for investigated compounds on different stationary phases from the relationships $\log k$ versus volume fraction of organic modifier in the mobile phase $(\varphi)$

\begin{tabular}{|c|c|c|c|c|c|c|c|c|c|c|c|c|c|c|c|}
\hline \multicolumn{4}{|c|}{ Zorbax XDB C18/MeOH } & \multicolumn{4}{|c|}{ Zorbax XDB C18/ACN } & \multicolumn{4}{|c|}{ UDC Cogent Cholesterol/MeOH } & \multicolumn{4}{|c|}{ UDC Cogent Cholesterol/ACN } \\
\hline $\log k_{\mathrm{w}}$ & $S$ & $\varphi_{\mathrm{o}}$ & $\mathrm{R}^{2}$ & $\log k_{\mathrm{w}}$ & $S$ & $\varphi_{\mathrm{o}}$ & $\mathrm{R}^{2}$ & $\log k_{\mathrm{w}}$ & $S$ & $\varphi_{\mathrm{o}}$ & $\mathrm{R}^{2}$ & $\log k_{\mathrm{w}}$ & $S$ & $\varphi_{\mathrm{o}}$ & $\mathrm{R}^{2}$ \\
\hline 2.85 & 3.51 & 0.81 & 0.99 & 1.20 & 1.80 & 0.66 & 0.99 & 4.21 & 4.75 & 0.88 & 0.97 & 1.26 & 1.45 & 0.86 & 0.98 \\
\hline 3.51 & 4.20 & 0.83 & 0.99 & 1.39 & 1.77 & 0.78 & 0.96 & 3.55 & 3.67 & 0.96 & 0.98 & 2.42 & 1.88 & 1.28 & 0.93 \\
\hline 5.33 & 5.72 & 0.93 & 0.99 & 3.50 & 4.05 & 0.86 & 0.99 & 3.43 & 3.63 & 0.94 & 0.99 & 3.07 & 3.51 & 0.87 & 0.99 \\
\hline 3.65 & 4.33 & 0.84 & 0.99 & 2.31 & 2.99 & 0.77 & 0.99 & 3.36 & 3.80 & 0.88 & 0.99 & 2.02 & 2.50 & 0.80 & 0.99 \\
\hline 4.44 & 5.18 & 0.85 & 0.99 & 1.89 & 2.36 & 0.80 & 0.99 & 3.89 & 3.98 & 0.97 & 0.99 & 2.40 & 1.73 & 1.38 & 0.97 \\
\hline 2.63 & 3.52 & 0.74 & 0.99 & 2.55 & 3.05 & 0.83 & 0.99 & 3.87 & 4.04 & 0.95 & 0.99 & 2.41 & 2.70 & 0.89 & 0.99 \\
\hline 4.57 & 5.50 & 0.83 & 0.99 & 1.80 & 2.39 & 0.75 & 0.99 & 2.79 & 3.21 & 0.86 & 0.99 & 1.67 & 1.90 & 0.87 & 0.98 \\
\hline 4.04 & 5.02 & 0.80 & 0.99 & 1.86 & 2.51 & 0.74 & 0.99 & 2.93 & 3.11 & 0.94 & 0.99 & 1.87 & 2.17 & 0.86 & 0.99 \\
\hline 3.68 & 4.30 & 0.85 & 0.99 & 1.44 & 1.75 & 0.82 & 0.97 & 3.56 & 3.50 & 1.01 & 0.99 & 3.01 & 2.40 & 1.25 & 0.98 \\
\hline 3.90 & 4.89 & 0.79 & 0.99 & 1.85 & 2.51 & 0.73 & 0.99 & 2.78 & 3.01 & 0.92 & 0.99 & 1.81 & 2.14 & 0.84 & 0.99 \\
\hline 4.82 & 5.71 & 0.84 & 0.99 & 2.04 & 2.58 & 0.79 & 0.99 & 2.90 & 3.33 & 0.87 & 0.99 & 1.82 & 2.11 & 0.86 & 0.99 \\
\hline 5.03 & 5.95 & 0.84 & 0.99 & 2.55 & 3.09 & 0.82 & 0.99 & 3.65 & 3.84 & 0.95 & 0.99 & 2.35 & 2.69 & 0.87 & 0.99 \\
\hline 0.75 & 1.54 & 0.48 & 0.98 & -0.12 & 0.63 & 0.19 & 0.95 & 0.66 & 0.81 & 0.82 & 0.99 & 0.36 & 0.73 & 0.50 & 0.97 \\
\hline 0.77 & 1.59 & 0.48 & 0.98 & -0.03 & 0.72 & -0.04 & 0.90 & 0.62 & 0.76 & 0.82 & 0.99 & 0.22 & 0.50 & 0.43 & 0.99 \\
\hline 2.73 & 3.79 & 0.72 & 0.99 & 1.42 & 2.35 & 0.60 & 0.99 & 1.67 & 2.07 & 0.81 & 0.99 & 1.15 & 1.70 & 0.67 & 0.99 \\
\hline 3.17 & 4.17 & 0.76 & 0.99 & 1.73 & 2.64 & 0.65 & 0.99 & 1.90 & 2.30 & 0.83 & 0.99 & 1.35 & 1.90 & 0.71 & 0.99 \\
\hline 2.86 & 3.95 & 0.72 & 0.99 & 1.54 & 2.55 & 0.60 & 0.99 & 1.71 & 2.09 & 0.82 & 0.99 & 1.17 & 1.73 & 0.67 & 0.99 \\
\hline 5.29 & 6.40 & 0.82 & 0.99 & 3.19 & 3.83 & 0.83 & 0.99 & 2.95 & 3.41 & 0.86 & 0.99 & 2.29 & 2.97 & 0.77 & 0.99 \\
\hline 3.44 & 4.50 & 0.76 & 0.99 & 1.84 & 2.72 & 0.67 & 0.99 & 2.04 & 2.43 & 0.83 & 0.99 & 1.43 & 2.04 & 0.70 & 0.99 \\
\hline 3.09 & 4.09 & 0.75 & 0.99 & 1.66 & 2.58 & 0.64 & 0.99 & 1.93 & 2.31 & 0.83 & 0.99 & 1.30 & 1.85 & 0.70 & 0.99 \\
\hline
\end{tabular}

2D (18), Dipole moment, D (19), Molar Volume (20), Polarizability (21), Molar refractivity (22), BBB (23), $\log \mathrm{S}(24), \mathrm{pH}=1.7$ (Stomach) (25), $\mathrm{pH}=4.6$ (Duodenum) (26), $\mathrm{pH}=6.5$ (Jejunum \& Ileum) $(27), \mathrm{pH}=7.4$ (Blood) (28), $\mathrm{pH}=8$ (Colon) (29), $\log k_{\mathrm{w}} \mathrm{C} 18 \mathrm{M}$ (30), S C18 M (31), $\varphi_{\mathrm{o}}$ C18 M (32), $\log k_{\mathrm{w}} \mathrm{C} 18 \mathrm{ACN}(33), \mathrm{S}$ C18 ACN (34), $\varphi_{\mathrm{o}}$ C18 ACN (35), $\log k_{\mathrm{w}}$ Chol M (36), S Chol M (37), $\varphi_{\mathrm{o}}$ Chol M (38), log $k_{\mathrm{w}}$ Chol ACN (39), S Chol ACN (40), $\varphi_{o}$ Chol ACN (41), 0,6 $\varphi$ M C18 (42), 0,65 $\varphi$ M C18 (43), 0,7 $\varphi$ M C18 (44), 0,75 $\varphi$ M C18 (45),

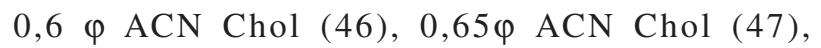

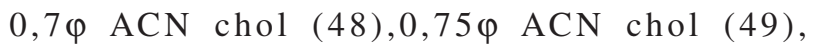
$0,8 \varphi$ ACN chol (50), 0,55 $\varphi$ ACN C18 (51), $0,6 \varphi$ ACN C18 (52), 0,65

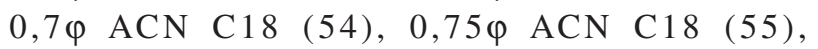

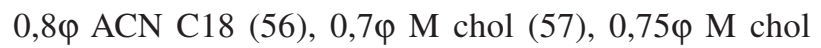
(58), $0,8 \varphi \mathrm{M}$ chol (59), $0,85 \varphi \mathrm{M}$ chol (60). A variable normalization before applying the PCA was performed.

\section{Results and Discussion}

The analysis covers 20 new synthesized urea derivatives (Figure 1). Chromatographic analysis was conducted in reversed phase systems on octadecyl silica and cholesterol phases by the use of organic aqueous eluent containing methanol and acetonitrile as organic modifiers. Most peaks of examined compounds provided good parameters of peak symmetry and efficiency. It should be emphasized, however, that peak symmetry was better for methanol containing eluent system on octadecyl silica stationary phase and for acetonitrile/water mobile phase on UDC Cholesterol column. Representative chromatograms visualizing above trends are illustrated in Figures $2 \mathrm{a}$ and $2 \mathrm{c}$. The two remaining systems enabled to obtain tailing peaks with a little bit worse symmetry (Figures $2 b$ and $2 d$ ). Moreover, it was observed that cholesterol stationary phase is more sensitive to change the kind of organic additive.

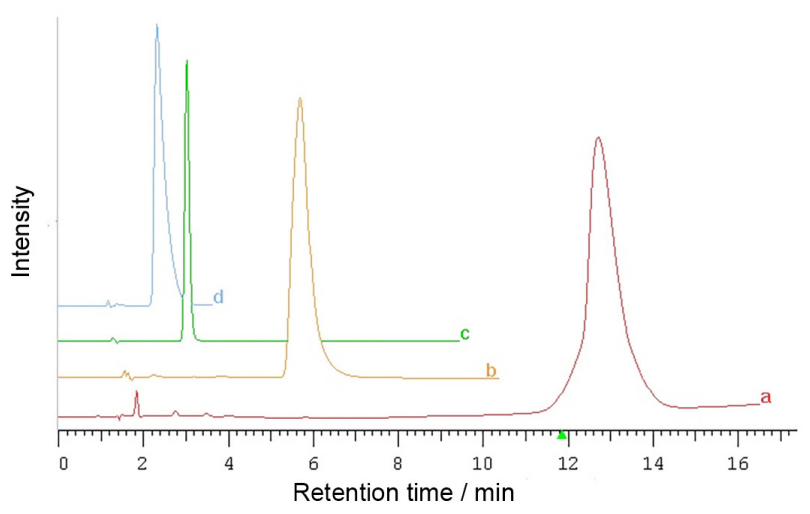

Figure 2. Comparison of peak parameters of compound 2 obtained on Cogent UDC Cholesterol using (a) $80 \%$ ACN/water, $\mathrm{N}=1810$, As = 1.31; (b) $80 \% \mathrm{MeOH} /$ water, $\mathrm{N}=1030$, As = 1.6; and on Zorbax Eclipse XDB-C18 by the use of (c) $80 \% \mathrm{MeOH} /$ water, $\mathrm{N}=3700$, As = 1.14; (d) $80 \% \mathrm{ACN} /$ water $\mathrm{N}=500, \mathrm{As}=2.95 . \mathrm{N}$ : theoretical plates number; As: asymmetry factor. 
Changing the mobile phase from $80 \%$ methanol into $80 \%$ acetonitrile on $\mathrm{C} 18$ column caused $0.72 \mathrm{~min}$ of difference in retention time, whereas on cholesterol stationary phase this difference was almost ten times longer (6.98 $\mathrm{min})$.

Relationships between $\log k$ and $\varphi$ (the volume fraction of organic solvent in the eluent) were established for both eluents on tested stationary phases. Organic solvent concentration was ranging from 0.55 to $0.80 \varphi$ with 0.05 increments for $\mathrm{C} 18$ column whereas cholesterol stationary phase required acetonitrile concentration from 0.60 to 0.80 and methanol from 0.70 to $0.85 \varphi$ in order to ensure $k$ value at acceptable level $(k<10)$.

In all cases, the dependences of $\log k v s . \varphi$ were linear with the squared correlation coefficients greater than 0.9. It can be assumed that the obtained chromatographic lipophilicity parameters $\log k_{\mathrm{w}}, S$ and $\varphi_{0}$ were burdened with a small error and could be utilized as an independent, credible lipophilicity scale. Table 2 contains all parameters obtained experimentally on Zorbax Eclipse XDB-C18 and Cogent UDC Cholesterol.

Correlations between the intercept values determined for both eluent systems can be described by the following equations for examined columns, Zorbax Eclipse XDB-C18 and Cogent UDC Cholesterol, respectively:

$$
\begin{aligned}
& \log k_{\mathrm{w}}(\mathrm{MeOH})=(1.2511 \pm 0.18) \log k_{\mathrm{w}}(\mathrm{ACN})+ \\
& (1.2989 \pm 0.35) \\
& \mathrm{n}=20, \mathrm{r}=0.8528, \mathrm{~s}=0.68, \mathrm{~F}=48.02 \\
& \log k_{\mathrm{w}}(\mathrm{MeOH})=(1.1204 \pm 0.18) \log k_{\mathrm{w}}(\mathrm{ACN})+ \\
& (0.7394 \pm 0.35) \\
& \mathrm{n}=20, \mathrm{r}=0.8192, \mathrm{~s}=0.62, \mathrm{~F}=36.74
\end{aligned}
$$

where $\mathrm{n}$ stands for the number of the compounds; $\mathrm{r}$ is the correlation coefficient; $\mathrm{s}$ is the standard deviation and $\mathrm{F}$ is the Fisher's test.

The presented results reveal that $\log k_{\mathrm{w}}$ values correlate with each other. In case of Cogent UDC Cholesterol, correlation is a little bit worse considering lower correlation coefficient and Fisher's factor. It appears that due to the exclusion of the first compound from this dependence, correlation coefficient significantly increases into the following one:

$$
\begin{aligned}
& \log k_{\mathrm{w}}(\mathrm{MeOH})=(1.2235 \pm 0.11) \log k_{\mathrm{w}}(\mathrm{ACN})+ \\
& (0.4449 \pm 0.21) \\
& \mathrm{n}=19, \mathrm{r}=0.9377, \mathrm{~s}=0.36, \mathrm{~F}=123.77
\end{aligned}
$$

Excluded compound, 1-(1-aryl-4,5-dihydro-1 $H$ imidazo)-3-(4-methylobenzyl) urea, differs from the others by the absence of methyl substituent in the imidazole ring. This structure involves stronger solvation with ACN and lower affinity for cholesterol stationary phase. In consequence, $\log k_{\mathrm{w}}$ parameter is almost four times smaller in acetonitrile containing eluent in comparison to methanol on Cogent UDC Cholesterol column.

In turn, the derivative containing ester polar substituent at R1 position (number 6), namely 1-[1-methyl-4-(4methylphenyl)4,5-dihydro- $1 \mathrm{H}$-imidazo]-3-(4-ethoxycarbonylphenyl) urea, acts as an outlier in conventional reversed-phase system. Owing to removing this compound, the above correlation can also be improved into the following one:

$\log k_{\mathrm{w}}(\mathrm{MeOH})=(1.3607 \pm 0.14) \log k_{\mathrm{w}}(\mathrm{ACN})+$ $(1.2052 \pm 0.27)$

$\mathrm{n}=19, \mathrm{r}=0.9199, \mathrm{~s}=0.51, \mathrm{~F}=93.60$

For comparison of the free energies of the partition processes occurring on both columns, lipophilicity parameters could be cross-correlated. ${ }^{32}$ Relationship between $\log k_{\mathrm{w}}$ values is expressed by the equation:

$\log k_{\mathrm{w}}(\mathrm{C} 18 / \mathrm{MeOH})=(1.6422 \pm 0.20) \log k_{\mathrm{w}}($ Cholesterol $/ \mathrm{ACN})+(0.8326 \pm 0.36)$ $\mathrm{n}=18 ; \mathrm{r}=0.8989 ; \mathrm{s}=0.59, \mathrm{~F}=67.35$

Despite satisfactory correlation of obtained lipophilicity parameters $(r=0.8989)$, it should be emphasized that the slope of the above relationship (1.6422) is far from unity, indicating that the energies of retention between compared chromatographic systems are not equivalent. Furthermore, the variation observed in the intercept indicates a substantial difference in the phase ratios of both columns.

Visual examination of the curve in Figure 3 illustrating $\log k_{\mathrm{w}}(\mathrm{C} 18 / \mathrm{MeOH}) v s \cdot \log k_{\mathrm{w}}(\mathrm{Cholesterol} / \mathrm{ACN})$ relationship made it possible to distinguish two outliers (compounds $\mathbf{6}$ and 9) possessing cyclopentyl and ethoxycarbonyl substituents. The obtained results show that despite the fact that the retention mechanisms are heteroenergetic, conventional C18 column and methanol containing eluent system and cholesterol phase with acetonitrile/water mobile phase can be used as equivalent models of the partition system for a set of diverse urea derivatives.

In the case of congeneric group of compounds, the intercept to slope ratio should be constant. Excellent statistical correlation between these indices was obtained by Natalini et $a l . .^{33}$ and Flieger $e t a l .{ }^{34}$ In order to demonstrate the structural similarity of the tested compounds that undergo retention in accordance with the same uniform retention mechanism, the relationship between $\log k_{\mathrm{w}}$ and $S$ was investigated for both studied systems. Obtained linear 


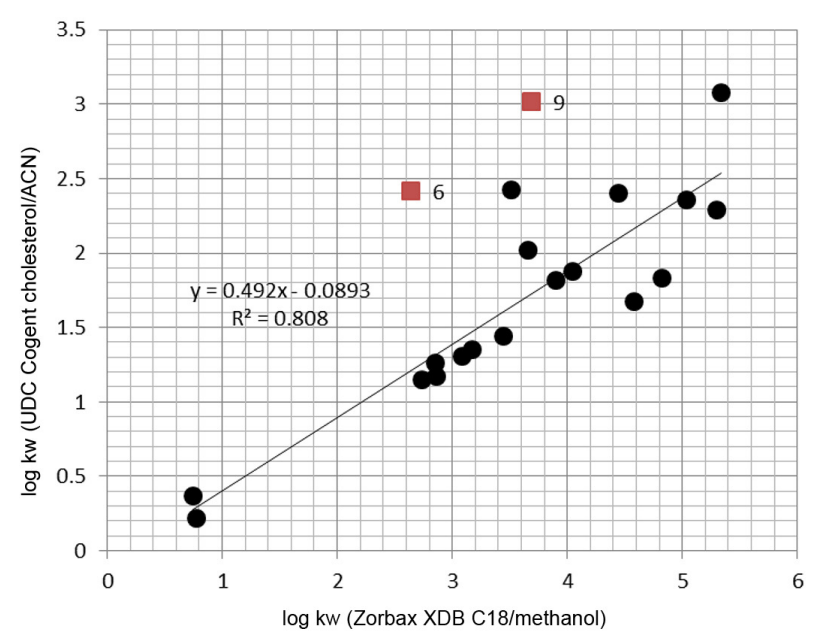

Figure 3. Relationship between $\log k_{\mathrm{w}}$ values obtained by the use of different chromatographic systems: Zorbax XDB C18 with methanolwater eluent and UDC Cogent cholesterol with acetonitrile-water mobile phase. The $\mathbf{6}$ and $\mathbf{9}$ numbers denote compounds acting as outliers from the presented relationship.

regression equations were significant only in the case of the octadecyl bonded phase and methanol containing eluent system:

$\log k_{\mathrm{w}}=(-0.9869 \pm 0.03) S-(0.8072 \pm 0.15)$

$\mathrm{n}=20 ; \mathrm{r}=0.9891 ; \mathrm{s}=0.19 ; \mathrm{F}=814.77$

Despite insignificant correlation between $\log k_{\mathrm{w}}$ and $S$ for the cholesterol column in combination with acetonitrile containing eluent system, it was possible to notice that excluding $N$-methyl substituted derivatives possessing the most hydrophobic functional groups at $\mathrm{R} 1$ position such as $\mathrm{CH}_{2} \mathrm{CH}_{2} \mathrm{C}_{6} \mathrm{H}_{5}, \mathrm{C}_{5} \mathrm{H}_{9}$ numbers 2,5,9, correlation between $\log k_{\mathrm{w}}$ and $S$ for cholesterol column becomes also statistically significant:

$$
\begin{aligned}
& \log k_{\mathrm{w}}=(-0.9517 \pm 0.05) S-(0.3151 \pm 0.11) \\
& \mathrm{n}=17 ; \mathrm{r}=0.9804 ; \mathrm{s}=0.15 ; \mathrm{F}=370.28
\end{aligned}
$$

Summarizing the above results it could be emphasized that hydrophobic effect governing adsorption process on C18 stationary phase with methanol-water eluent is disturbed by molecule containing polar substituent at R1 position. Excluded compound with ester polar functional group acting among others as steric hindrance confirms the statement of Minick et al..$^{35}$ that RPLC separates compounds into classes according to hydrogen bonding properties. Discrimination of ester (hydrogen bond acceptor) demonstrates that this chromatographic system is sensitive to hydrogen-bonding differences between noncongeners appearing among urea derivatives.

In contrast, for UDC Cholesterol column applied with acetonitrile-water mobile phase, correlation between $\log k_{\mathrm{w}}$ and $S$ improves after removing solutes with more non-polar substituents due to their worse fitting to the regression line. One could conclude that cholesterol column with acetonitrile-water eluent system is preferable for illustrating similarity of compounds with more polar even enable to ionization substituents.

Significant correlations presented above prove that the retention process of the most urea derivatives is governed by the similar intermolecular forces on examined stationary phases differing, however, with each other. Additionally, it should be noted that the slope in all cases is close to unity $(0.9868,0.9517)$, proving similarity of compared parameters.

The correlations between parameters obtained theoretically and experimentally were investigated by PCA analysis. From that investigation one may infer that the first two principal components carry the most important information. Together at each case they explain a great part, as much as above $80 \%$, of the variance. Graph on Figure $4 \mathrm{a}$ shows the great contribution of all original variables to the principal components except dipole moment (variable 19) and VDW surface donor (variable 17).
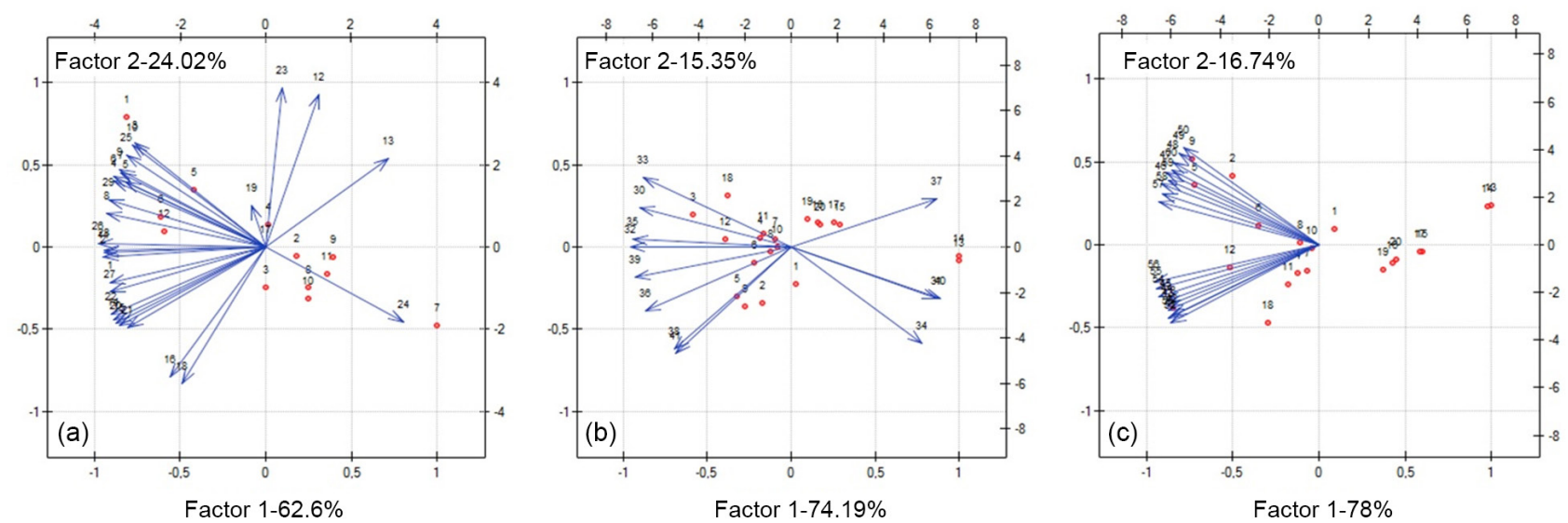

Figure 4. Biplots present the vectors of original variables: (A) 1-29: theoretically calculated descriptors; (B) 30-41: chromatographic lipophilicity parameters; (C) 42-60: all retention data; and points presenting particular compounds (1-20) placed in a coordinate system defined by 2 principal components. 
The points carry the information about particular compounds. As it can be seen, compounds number $\mathbf{1}$ and $\mathbf{7}$ are at a large distance from the others. For point 7 , reversible to the first compound, the value of the first component is much greater than the average and the value of the second component is much smaller than the average. Considering the fact that the $\log \mathrm{D}$ values at $\mathrm{pH}=4.6$ (Duodenum) has the largest contribution in the first component and the second one is dependent on AlogP, one can conclude that compounds number $\mathbf{1}$ and $\mathbf{7}$ become outliers mainly due to these descriptors.

PCA of chromatographic lipophilicty parameters (Figure 4B) revealed the following best relationships: $S$ (C18 column and methanol containing mobile phase) vs. $S$ (cholesterol column and acetonitrile in the mobile phase); $S$ (C18 column and acetonitrile containing mobile phase) vs. $\log k_{\mathrm{w}}$ (C18 column and acetonitrile containing mobile phase); $\log k_{\mathrm{w}}$ (cholesterol column and acetonitrile in the mobile phase) vs. $S$ (cholesterol column and methanol in the mobile phase); $S$ (C18 column and methanol containing mobile phase) $v s . \log k_{\mathrm{w}}$ (C18 column and acetonitrile containing mobile phase); $S$ (cholesterol column and acetonitrile in the mobile phase) $v s . \log k_{\mathrm{w}}$ (C18 column and acetonitrile containing mobile phase). Despite the high statistical significance of the above correlation, it would be difficult to find a rational explanation for them.

Most interesting is the relationship between $\varphi_{0}$ values obtained on the octadecyl bonded phase (variables number 35, 32) and cholesterol phase (variables 38, 41) highly correlated indicating that this parameter $\left(\varphi_{0}\right)$ is independent on the organic modifier in the mobile phase. Similar conclusion was obtained by Natalini et $a l .^{33}$ for a series of bile acids. Biplot on Figure 4B shows two outliers 13 and 14. Both compounds are 1-(1-oxido-1,2,4benzotriazin-3-ylo)-3-arylalkilureas. By projecting the points onto the lines which extend the vectors of original values, the reasons can be possibly found. High and positive values on the projection onto the original value of the first component depend mainly on $\varphi_{0}$ measured on C 18 column and methanol containing mobile but small values of the remaining original values (negative values on the projection onto the extension of the vectors illustrating the remaining original dependent on the $\log k_{\mathrm{w}}$ values determined on C18 column and acetonitrile containing mobile).

Figure 4C shows PCA of all retention data $(\log k)$ measured by polycratic methods on both columns. The vectors are placed on a plane defined appropriate by the two selected principal components. Vector lengths are comparable involving comparable contribution of the original variable to the components. Considering the angle between vectors indicating the correlation of original values it should be noted that vectors are separated into highly correlated groups. Upper vectors represent chromatographic data measured on cholesterol column, whereas lower vectors belong to parameters determined by the use of Zorbax XDB C18 column. Considering the significance of Euclidean distances between the points the information carried by compounds can be compared. Once again, compounds number 13 and 14 being 1-(1-oxido1,2,4-benzotriazin-3-ylo)-3-arylalkilurea derivatives formed separated group. Additionally, derivatives of ethyl\{[(1-aryl-2-arylsulfonylimidazolidin-2-ylidene)carbamoyl]-amino \}-acetate (structure 8) created another cluster, except compound number 18 possessing the most hydrophobic (2,3-methyl) substituents in this group. Interesting localization concerns compound number 9. For this compound higher contribution of second component representing retention on cholesterol column eluted by $0.65 \varphi$ acetonitrile in water is visible. This compound appears again as an outlier. Its structure is characterized by all hydrophobic substituents: $\mathrm{CH}_{3}, \mathrm{CH}_{3}$ and $\mathrm{C}_{5} \mathrm{H}_{9}$.

PCA of theoretical parameters (1-29 variables) and chromatographic lipophilicity parameters $\log k_{\mathrm{w}}, S$ and $\varphi_{0}$ values (30-41 variables) is presented on Figure 5.

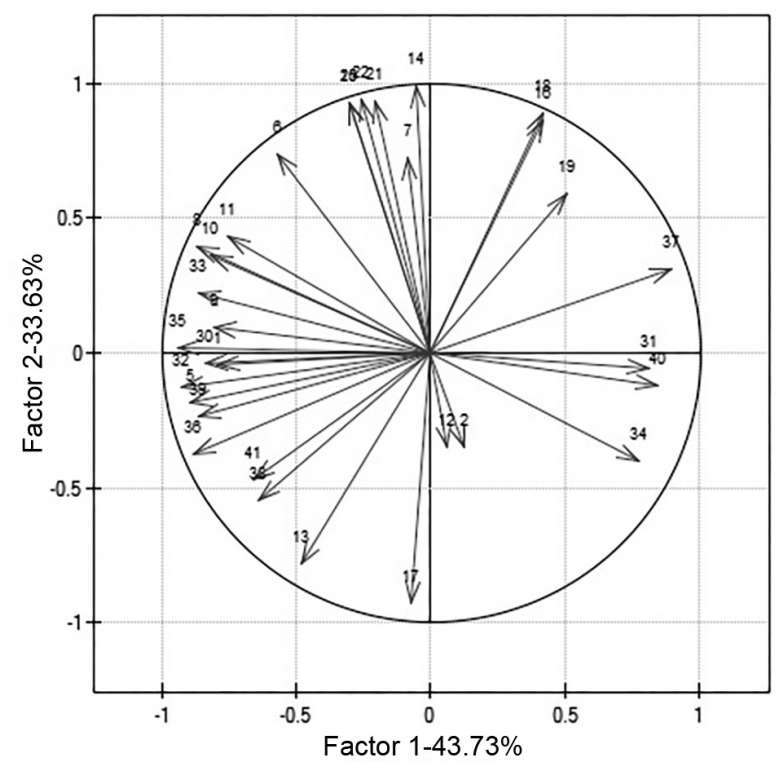

Figure 5. Factor loadings graph. The vectors represent original variables: theoretical descriptors number 1-29 presented in Tables 1, S1, S2; chromatographic lipophilicity parameters number $30-41$ collected in Table 2.

The correlation between them was of lower quality except $S$ value determined in methanol/water eluent system on cholesterol column and $\log P$ values calculated by fragmental method KowWIN. It appeared that the above fragment-based approach comprising electronic interactions within one fragment guarantees statistically 


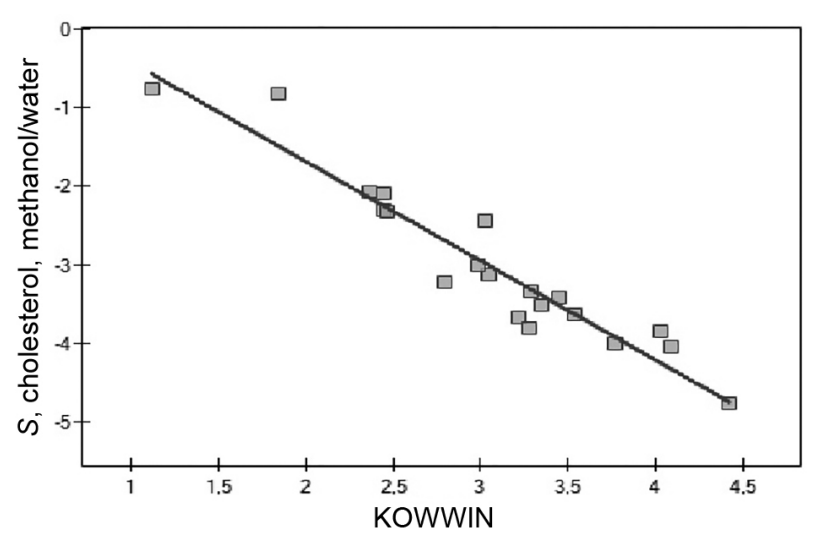

Figure 6. Relationship between $S$ value determined on cholesterol column and $\mathrm{MeOH} /$ water eluent system and $\log P$ KOWWIN theoretically calculated.

significant correlation with chromatographic lipophilicity scale. Finally, Pearson correlation is illustrated graphically in Figure 6 and is described by the following equation:

$S($ Cholesterol $/ \mathrm{MeOH})=(-1.2609 \pm 0.93)$

$\log P$ KOWWIN $+(0.8359 \pm 0.29)$

$\mathrm{n}=20, \mathrm{r}=0.9547 \pm 0.07, \mathrm{~s}=0.31, \mathrm{~F}=185.72$

\section{Conclusions}

A chromatographic study of newly synthesized urea derivatives was undertaken. The reversed-phase materials: a Zorbax Extend-C18 and Cogent UDC were applied under varying solvents. Nowadays, cholesterol columns are becoming more and more popular..$^{36-39}$ In the presented work, by comparing conventional octadecyl bonded phase with cholesterol column, confirms the suitability of cholesterol stationary phase for chromatographic analysis of urea derivatives and determination of their lipophilicity. It should be emphasized that to achieve better efficiency of chromatographic system containing cholesterol stationary phase, acetonitrile can be recommended in analysis of urea derivatives. It was proved that although the retention mechanism on cholesterol phase and conventional octadecyl silica phase at aqueous-organic mobile phase differs from each other, both systems reveal congenericity of examined compounds. Plots of log $k$ versus organic solvent content in the mobile were constructed with an aim to determine lipophilicity parameters on both columns studied. Only Cogent UDC Cholesterol column appeared to be a source of parameters significantly correlating with theoretically calculated $\log P$ values applying fragmental method. This model can be successfully used in either lipophilicity prediction or passive transport through the biological phospholipids barriers anticipation of urea derivatives.

\section{Supplementary Information}

Supplementary Information (Table S1: structural parameters: HOMO: highest occupied molecular orbital; LUMO: lowest unoccupied molecular orbital; TPSA: topological polar surface area; BBB: blood-brain barrier permeation; log S: solubility; VDW: van der Waals and Table S2: distribution, $\log \mathrm{D}$ at different $\mathrm{pH}$ ) is available free of charge at http://jbcs.sbq.org.br.

\section{Acknowledgments}

The paper was developed using the equipment purchased within the project "The equipment of innovative laboratories doing research on new medicines used in the therapy of civilization and neoplastic diseases" of the Operational Program Development of Eastern Poland 2007-2013, Priority Axis I modern Economy, operations I.3 Innovation promotion. The research was partially performed during the postdoctoral fellowship of Agnieszka A. Kaczor at University of Eastern Finland, Kuopio, Finland, under Marie Curie fellowship. Part of the calculations was performed under a computational grant by Interdisciplinary Center for Mathematical and Computational Modelling (ICM), Warsaw, Poland, grant number G30-18 and under resources and licenses by CSC, Finland.

\section{References}

1. Mannhold, R.; Poda, G. I.; Ostermann, C.; Tetko, I. V.; J. Pharm. Sci. 2009, 98, 861.

2. Pajouhesh, H.; Lenz, G. R.; NeuroRx 2005, 2, 541.

3. Hansch, C.; Leo, A.; Hoekman, D.; Hydrophobic, Electronic, and Steric Constants, $1^{\text {st }}$ ed.; American Chemical Society: Washington, DC, 1995.

4. Flieger, J.; Tatarczak-Michalewska, M.; Wujec, M.; Pitucha, M.; Świeboda, R.; J. Pharm. Biomed. Anal. 2015, 107, 501.

5. Flieger, J.; Czajkowska-Żelazko, A.; Rządkowska, M.; Szacoń, E.; Matosiuk, D.; J. Pharm. Biomed. Anal. 2012, 66, 58.

6. Flieger, J.; J. Chromatogr. A 2010, 1217, 540.

7. Kaliszan, R.; Trends Anal. Chem. 1999, 18, 400.

8. Andrić, F.; Héberger, K.; J. Pharm. Biomed. Anal. 2015, 115, 183.

9. Mrkvičková, Z.; Kovaříková, P.; Balíková, S.; Klimeš, J.; J. Pharm. Biomed. Anal. 2008, 48, 310.

10. Darrouzain, F.; Dallet, P.; Dubost, J.-P.; Ismaili, L. F.; Pehourcq, B.; Bannwarth, M.; Matoga, Y. C.; J. Pharm. Biomed. Anal. 2006, 41, 228.

11. Liu, X.; Tanaka, H.; Yamauchi, A.; Testa, B.; Chuman, H.; Helv. Chim. Acta. 2004, 87, 2866. 
12. Liu, X.; Tanaka, H.; Yamauchi, A.; Testa, B.; Chuman, H.; J. Chromatogr. A 2005, 1091, 51.

13. Soczewinski, E.; Wachtmeister, C. A.; J. Chromatogr. 1962, 7 , 311.

14. Snyder, L. R.; Dolan, J. W.; Gant, J. R.; J. Chromatogr. 1979, $165,3$.

15. D’Archivio, A. A.; Maggi, M. A.; Mazzeo, P.; Ruggieri, F.; Anal. Chim. Acta 2008, 628, 162.

16. D’Archivio A. A.; Maggi M. A.; Ruggieri F.; J. Sep. Sci. 2010, $33,155$.

17. Valko, K.; Slegel, P.; J. Chromatogr. A 1993, 631, 49.

18. Natalini, B.; Sardella, R.; Gioiello, A.; Rosatelli, E.; Ianni, F.; Camaioni, E.; Anal. Bioanal. Chem. 2011, 401, 267.

19. Stasiak, J.; Koba, M.; Bober, L.; Kawczak, P.; Bạczek, T.; Comb. Chem. High Throughput Screening 2013, 16, 603.

20. Yamagami, C.; Araki, K.; Ohnishi, K.; Hanasato, K.; Inaba, H.; Aono, M.; Ohta, A.; J. Pharm. Sci. 1999, 88, 1299.

21. Ruiz-Angel, M. J.; Carda-Broch, S.; García-Alvarez-Coque, M. C.; Berthod, A.; J. Chromatogr. A 2005, 1063, 25.

22. Lu, D.; Chambers, P.; Wipf, P.; Xie, X.-Q.; Englert, D.; Weber, S.; J. Chromatogr. A 2012, 1258, 161.

23. Al-Haj, M. A.; Haber, P.; Kaliszan, R.; Buszewski, B.; Jezierska, M.; Chilmonczyk, Z.; J. Pharm. Biomed. Anal. 1998, 18, 721.

24. Buszewski, B.; Jezierska, M.; Wełniak, M.; Kaliszan, R.; J. Chromatogr. A 1999, 845, 433.

25. Pesek, J. J.; Siouffi, A. M.; Anal. Chem. 1989, 61, 1928.

26. Hansch, C.; Maloney, P.; Fujita, T.; Muir, M.; Nature 1962, 194, 178.

27. Szacoń, E.; Rządkowska, M.; Kaczor, A. A.; Kędzierska, E.; Fidecka, S.; Matosiuk, D.; Molecules 2015, 20, 3821.

28. Becke, A.; J. Chem. Phys. 1993, 98, 5648.

29. Lee, C.; Yang, W.; Parr, R. G.; Phys. Rev. B: Condens. Matter Mater. Phys. 1988, 37, 785.

30. Frisch, M. J.; Trucks, G. W.; Schlegel, H. B.; Scuseria, G. E.; Robb, M. A.; Cheeseman, J. R.; Scalmani, G.; Barone, V.; Mennucci, B.; Petersson, G. A.; Nakatsuji, H.; Caricato, M.; Li, X.; Hratchian, H. P.; Izmaylov, A. F.; Bloino, J.; Zheng,
G.; Sonnenberg, J. L.; Hada, M.; Ehara, M.; Toyota, K.; Fukuda, R.; Hasegawa, J.; Ishida, M.; Nakajima, T.; Honda, Y.; Kitao, O.; Nakai, H.; Vreven, T.; Montgomery, J. A., Jr.; Peralta, J. E.; Ogliaro, F.; Bearpark, M.; Heyd, J. J.; Brothers, E.; Kudin, K. N.; Staroverov, V. N.; Kobayashi, R.; Normand, J.; Raghavachari, K.; Rendell, A.; Burant, J. C.; Iyengar, S. S.; Tomasi, J.; Cossi, M.; Rega, N.; Millam, N. J.; Klene, M.; Knox, J. E.; Cross, J. B.; Bakken, V.; Adamo, C.; Jaramillo, J.; Gomperts, R.; Stratmann, R. E.; Yazyev, O.; Austin, A. J.; Cammi, R.; Pomelli, C.; Ochterski, J. W.; Martin, R. L.; Morokuma, K.; Zakrzewski, V. G.; Voth, G. A.; Salvador, P.; Dannenberg, J. J.; Dapprich, S.; Daniels, A. D.; Farkas, Ö.; Foresman, J. B.; Ortiz, J. V.; Cioslowski, J.; Fox, D. J.; Gaussian 09, Revision D.01, Gaussian, Inc.: Wallingford, CT, 2009.

31. Virtual Computational Chemistry Laboratory, www.vcclab.org, accessed on April 2016.

32. Minick, D. J.; Brent, D. A.; Frenz, J.; J. Chromatogr. 1989, 461, 177.

33. Natalini, B.; Sardella, R.; Camaioni, E.; Macchiarulo, A.; Gioiello, A.; Carbone, G.; J. Pharm. Biomed. Anal. 2009, 50, 613.

34. Flieger, J.; Tatarczak-Michalewska, M.; Wujec, M.; Pitucha, M.; Świeboda, R.; J. Pharm. Biomed. Anal. 2015, 107, 501.

35. Minick, D. J.; Frenz, J. H.; Patrick, M. A.; Brent, D. A.; J. Med. Chem. 1988, 31, 1923.

36. Al-Haj, M. A.; Haber, P.; Kaliszan, R.; Buszewski, B.; Jezierska, M.; Chilmonczyk, Z.; J. Pharm. Biomed. Anal. 1998, 18, 721.

37. Buszewski, B.; Jezierska, M.; Wełniak, M.; Kaliszan, R.; J. Chromatogr. A 1999, 845, 433.

38. Kaliszan, R.; Kaliszan, A.; Wainer, I. W.; J. Pharm. Biomed. Anal. 1993, 11, 505.

39. Kaliszan, R.; Nasal, A.; Bucinski, A.; Eur. J. Med. Chem. 1994, 29, 163.
Submitted: February 18, 2016 Published online: April 27, 2016 